\title{
Tinjauan Kemampuan Berpikir Kritis dalam Model Pembelajaran Inkuiri dan Pengaruhnya Terhadap Hasil Belajar
}

\author{
Fera Widi Astuti ${ }^{1)}$, Firjon Separtagus ${ }^{2)}$, Shohibi ${ }^{\text {3) }}$ \\ ${ }^{1)}$ SMAN Plus Sukowono, ${ }^{2}$ SMK Medika Farma Kalisat, ${ }^{3}$ SMA Satya Dharma \\ Email: ferawa@gmail.com, firjons.h@gmail.com,shohibi1979@gmail.com
}

\begin{abstract}
This research is a causal quantitative study that wants to know the application of inquiry learning models and the ability to think critically the effect on learning outcomes. The problems examined in this study are: 1) is there an influence of inquiry learning models on learning outcomes? 2) is there an influence on critical thinking skills on learning outcomes, and 3) is there an influence on inquiry learning models and critical thinking skills together on learning outcomes? Objectives: 1) find out whether there is an influence of inquiry learning models on learning outcomes, 2) find out whether there is an influence of critical thinking skills on learning outcomes, 3 ) find out whether there is an influence of inquiry learning models and critical thinking skills together on learning outcomes. The respondents of this study were 66th grade students of IPA1 and IPA2 with 66 students in SMA Negeri Sukowono in the odd semester of the 2018/2019 academic year, taking samples using the population resech method. The study area was determined by the judgment area method. This research is a quantitative study with a causal design. Data collection tools using questionnaires, tests and documentation and interview aids. A valid and reliable degree of tool with validity and reliability tests. The instrument analysis test uses: 1) descriptive test, 2) normality test, 3) homogeneity test, 4) multicollinearity test, 5) heterokedasticity test. Hypothesis test with: 1) regression analysis, 2) F test, 3 ) $t$ test, 4) test the coefficient of determination (R2). The results showed that: 1) sig. of the inquiry learning model variable on learning outcomes 0,000 , the conclusion sig. $>0.05$, it means that there is an influence of inquiry learning model on learning outcomes, 2) the value of sig. of the variable ability to think critically on learning outcomes is 0,000 , the conclusion sig. $>0.05$, this means there is an influence of critical thinking skills on learning outcomes, 3) the results of the regression analysis output obtained Fcount 52.402 with sig. 0,000, because $>0.05$, there is an influence of inquiry learning models and critical thinking skills together on learning outcomes. Suggestions proposed for teachers to apply learning by using inquiry learning models and internal factor analysis of critical thinking skills because they can improve learning outcomes primarily in chemistry subjects.
\end{abstract}

Keywords : Critical Thinking Ability, Inquiry Learning Model, Learning Outcomes 


\begin{abstract}
ABSTRAK
Penelitian ini adalah penelitian kuantitatif kausal yang ingin mengetahui penerapan model pembelajaran inkuiri dan kemampuan berpikir kritis pengaruhnya terhadap hasil belajar. Permasalahan yang dikaji dalam penelitian ini adalah: 1) apakah ada pengaruh model pembelajaran inkuiri terhadap hasil belajar?, 2) apakah ada pengaruh kemampuan berpikir kritis terhadap hasil belajar, dan 3) apakah ada pengaruh model pembelajaran inkuiri dan kemampuan berpikir kritis secara bersamasama terhadap hasil belajar? Tujuan: 1)mengetahui adakah pengaruh model pembelajaran inkuiri terhadap hasil belajar, 2) mengetahui adakah pengaruh kemampuan berpikir kritis terhadap hasil belajar, 3)mengetahui adakah pengaruh model pembelajaran inkuiri dan kemampuan berpikir kritis secara bersama-sama terhadap hasil belajar. Responden penelitian ini adalah siswa kelas XI IPA1 dan IPA2 sejumlah 66 siswa di SMA Negeri Plus Sukowono semester ganjil tahun ajaran 2016/2017,pengambilan sampel menggunakan metode population resech .Daerah penelitian ditentukan dengan metode judgmen area. Penelitian ini merupakan penelitian kuantitatif dengan desain kausal. Alat pengumpul data menggunakan metode angket, tes serta metode bantu dokumentasi dan wawancara. Derajad valid dan reliabel alat dengan uji validitas dan reliabilitas. Uji analisis instrumen menggunakan: 1) uji deskriptif, 2) uji normalitas, 3) uji homogenitas,4) uji multikolinieritas,5) uji heterokedastisitas. Uji hipotesis dengan: 1) analisis regresi, 2) uji $F, 3)$ uji t, 4) uji koefisien determinasi $\left(\mathrm{R}^{2}\right)$. Hasil penelitian menunjukkan bahwa: 1) nilai sig. dari variabel model pembelajaran inkuiri terhadap hasil belajar 0.000 , kesimpulan sig. > 0,05, berarti terdapat pengaruh model pembelajaran inkuiri terhadap hasil belajar, 2) nilai sig. dari variabel kemampuan berpikir kritis terhadap hasil belajar adalah 0.000, kesimpulan sig. > 0,05, ini berarti terdapat pengaruh kemampuan berpikir kritis terhadap hasil belajar, 3) hasil output analisis regresi diperoleh $F_{\text {hitung }} 52.402$ dengan sig. 0,000, karena >0,05 maka terdapat pengaruh model pembelajaran inkuiri dan kemampuan berpikir kritis secara bersama-sama terhadap hasil belajar. Saran yang diajukan agar para guru menerapkan pembelajaran dengan menggunakan model pembelajaran inkuiri dan analisis faktor internal kemampuan berpikir kritis karena dapat meningkatkan hasil belajar utamanya pada mata pelajaran kimia.
\end{abstract}

Kata Kunci : Kemampuan Berpikir Kritis, Model Pembelajaran Inkuiri, Hasil Belajar

\title{
PENDAHULUAN
}

Kualitas kehidupan bangsa sangat ditentukan oleh faktor pendidikan, oleh karena itu diperlukan pembaharuan pendidikan untuk meningkatkan mutu pendidikan, untuk mencapai itu pendidikan harus adaptif terhadap perubahan jaman. Konteks pembaharuan dalam pendidikan ada tiga hal utama yang perlu diperhatikan yaitu perubahan kurikulum, peningkatan kualitas pembelajaran dan efektifitas metode pembelajaran. Dunia pendidikan kita kurang memberikan kesempatan 
kepada siswa dalam berbagai mata pelajaran untuk mengembangkan kemampuan berpikir holistik (menyeluruh), kreatif, objektif dan logis. Pendekatan pembelajaran masih didominasi oleh peran guru. Guru lebih banyak menempatkan siswa sebagai objek dan bukan sebagai subjek didik, serta kurang memperhatikan ketuntasan belajar secara individual.

Asam basa dan titrasi asam basa adalah salah satu materi kimia yang dipelajari pada siswa kelas XI. Selain harus memahami konsep, pada materi ini juga terdapat hitungan-hitungan yang harus dipahami siswa. Sebagian besar siswa dapat mengerjakan soal dan terlatih dalam perhitungan matematika saja, tetapi kurang memahami konsep kimia yang mendasari soal tersebut (Gabel, 2006). Oleh karena itu, pembelajaran asam basa dan titrasi asam basa sebaiknya lebih menekankan pada proses perolehan konsep.

Berdasarkan observasi saat proses pembelajaran di kelas, diketahui bahwa hanya sedikit siswa yang aktif. Siswa hanya bertanya untuk materi yang dianggap menarik saja namun untuk materi yang kurang menarik, siswa hanya mendengar dan mencatat penjelasan guru. Siswa juga masih merasa kesulitan pada mata pelajaran kimia khususnya materi asam basa dan titrasi asam basa. Kemampuan siswa dalam berpikir kritis juga masih tergolong rendah, hal tersebut terlihat dari Hasil observasi peneliti yaitu pada saat siswa diminta untuk menjelaskan aplikasi asam basa dan titrasi asam basa dalam kehidupan sehari-hari, sebagian besar siswa tidak dapat menjawab pernyataan tersebut dengan tepat.

Salah satu upaya menciptakan siswa berpikir kritis adalah dengan model pembelajaran inkuiri. Model pembelajaran inkuiri ini diharapkan siswa lebih mudah memahami materi kimia, dan dapat menghubungkannya dengan kejadian sehari-hari. Pembelajaran inkuiri diterapkan agar siswa bebas mengembangkan konsep yang mereka pelajari bukan hanya sebatas materi yang dicatat saja kemudian dihafal (Yulianingsih \& Hadisaputro, 2013). Pengembangan kemampuan berpikir kritis melalui inkuiri yang didasarkan pada kegiatan merumuskan masalah hingga menemukan pemecahannya merupakan proses dalam pembelajaran inkuiri yang mengakibatkan siswa mempunyai keterampilan memecahkan masalah (Sidiq \& Prayitno, 2012). 
Penelitian Sochibin (2009) menunjukkan penerapan metode inkuiri dapat meningkatkan hasil belajar siswa. Hal ini karena metode pembelajaran inkuiri memberikan pengalaman langsung pada siswa serta melibatkan keaktifan siswa untuk menemukan konsepnya sendiri. Dengan pengalaman belajar yang baik, siswa dapat memahami konsep dengan baik pula. Selain itu, siswa dapat memiliki daya ingat yang lebih kuat dalam pemahaman konsep sehingga siswa mudah menyelesaikan masalah dan memberikan hasil belajar yang lebih baik. Hasil penelitian Malihah (2011) membuktikan bahwa metode pembelajaran inkuiri mampu meningkatkan hasil belajar IPA. Begitu juga dengan Anggareni (2013) yang menyatakan bahwa kemampuan berpikir kritis siswa berkembang lebih baik setelah penerapan metode pembelajaran inkuiri. Pendapat-pendapat tersebut menunjukkan bahwa model pembelajaran inkuiri dan kemampuan berpikir kritis dapat meningkatkan hasil belajar siswa.

Berdasarkan uraian di atas, terdapat kebutuhan untuk menerapkan model pembelajaran inkuiri dan kemampuan berpikir kritis dalam pembelajaran di sekolah, oleh karena itu penulis mengambil judul pengaruh model pembelajaran inkuiri dan kemampuan berpikir kritis terhadap hasil belajar siswa kelas XI IPA SMAN Plus Sukowono. Penelitian ini diharapkan mampu menjadi suatu model pembelajaran yang dapat mempengaruhi kemampuan berpikir kritis dan hasil belajar siswa tanpa menyampingkan kepentingan konsep.

\section{METODE PENELITIAN}

Responden penelitian ini adalah siswa kelas XI IPA1 dan IPA2 sejumlah 66 siswa di SMA Negeri Plus Sukowono semester ganjil tahun ajaran 2018/2019,pengambilan sampel menggunakan metode population resech .Daerah penelitian ditentukan dengan metode judgmen area. Penelitian ini merupakan penelitian kuantitatif dengan desain kausal. Alat pengumpul data menggunakan metode angket, tes serta metode bantu dokumentasi dan wawancara. Derajad valid dan reliabel alat dengan uji validitas dan reliabilitas. Uji analisis instrumen menggunakan: 1) uji deskriptif, 2) uji normalitas, 3) uji homogenitas,4) uji multikolinieritas,5) uji heterokedastisitas. Uji hipotesis dengan: 1) analisis regresi, 2) uji F, 3) uji t, 4) uji koefisien determinasi $\left(\mathrm{R}^{2}\right)$. 


\section{HASIL DAN PEMBAHASAN}

Tabel 1. Deskripsi Data

\begin{tabular}{|l|c|c|c|c|}
\hline \multirow{2}{*}{ Variabel } & \multicolumn{3}{|c|}{ Model Pembelajaran Inkuiri } \\
\cline { 2 - 5 } & \multicolumn{2}{|c|}{ XI AP 1 } & \multicolumn{2}{c|}{ XI AP 2 } \\
\hline Statistik & $\begin{array}{c}\text { Hasil Belajar } \\
\text { Kognitif }\end{array}$ & $\begin{array}{c}\text { Hasil Belajar } \\
\text { Afektif }\end{array}$ & $\begin{array}{c}\text { Hasil Belajar } \\
\text { Kognitif }\end{array}$ & $\begin{array}{c}\text { Hasil Belajar } \\
\text { Afektif }\end{array}$ \\
\hline N & 34 & 34 & 32 & 32 \\
\hline Rata-rata & 76,8 & 69,6 & 71,3 & 69,6 \\
\hline Standar Deviasi & 10,9 & 8,1 & 5,5 & 6,6 \\
\hline Nilai Terendah & 55 & 51,3 & 55 & 58,1 \\
\hline Nilai Tertinggi & 90 & 88,7 & 80 & 85 \\
\hline
\end{tabular}

Kondisi afektif siswa mempengaruhi keberhasilan pembelajaran pada ranah kognitif dan psikomotor. Peserta didik yang memiliki minat belajar dan sikap positif terhadap pelajaran akan merasa senang mempelajari mata pelajaran tertentu, sehingga dapat mencapai hasil pembelajaran yang optimal. Dari tabel 1 dapat diketahui kelas dengan proses pembelajaran menggunakan kegiatan laboratorium, rata-rata aspek afektifnya 69,6 dan standar deviasi 8,1 dengan nilai terendah 51,3 dan nilai tertinggi 88,7. Sedangkan kelas dengan proses pembelajaran menggunakan metode eksperimen, rata-rata aspek afektifnya 69,6 dan standar deviasi 6,6 dengan nilai terendah 58,1 dan nilai tertinggi 85. Secara keseluruhan kedua kelas mempunyai rata-rata 69,7 dan standar deviasi 7,4 dengan nilai terendah 51,2 dan nilai tertinggi 88,7.

Data hasil belajar siswa mata pelajaran kimia dengan mempertimbangkan kemampuan berpikir kritis dipaparkan sebagai berikut. Data kemampuan berpikir kritis dikelompokkan dalam dua kategori yaitu kemampuan berpikir kritis tinggi dan rendah. Nilai kemampuan berpikir kritis merupakan jumlah jawaban benar dari masing-masing siswa. Kemampuan berpikir kritis tinggi bagi siswa yang mempunyai nilai di atas rata-rata $(\geq)$ nilai kemampuan berpikir kritis seluruh kelas dan kemampuan berpikir kritis rendah bagi siswa yang mempunyai nilai di bawah ratarata $(\leq)$ kemampuan berpikir kritis seluruh kelas. Deskripsi data kemampuan berfikir kritis siswa terhadap hasil belajar ranah kognitif dapat dilihat pada Tabel 2 di bawah ini. 
Tabel 2. Data Nilai Kognitif Siswa Berdasarkan Kemampuan Berfikir Kritis

\begin{tabular}{|c|c|c|c|c|c|c|}
\hline $\begin{array}{l}\text { Kemampuan } \\
\text { Kritis }\end{array}$ & Berfikir & Mean & $\mathrm{N}$ & $\begin{array}{l}\text { Standar } \\
\text { Deviasi }\end{array}$ & rendah & tinggi \\
\hline Tinggi & & 74,6 & 36 & 6,2 & 55 & 90 \\
\hline Rendah & & 73,8 & 30 & 10,6 & 65 & 88 \\
\hline Total & & 74,1 & 66 & 9,1 & 55 & 90 \\
\hline
\end{tabular}

Data menunjukkan bahwa siswa yang mempunyai kemampuan berfikir kritis tinggi dengan jumlah 36 siswa mempunyai rata-rata 74,6, standar deviasi 6,2, nilai terendah 55, nilai tertinggi 90. Sedangkan siswa yang mempunyai kemampuan berfikir rendah dengan jumlah 30 siswa mempunyai rata-rata 73,8, standar deviasi 10,6, nilai terendah 60 dan nilai tertinggi 88. Data frekuensi kemampuan berfikir kritis siswa dapat dilihat pada Tabel 2.

Uji normalitas sebaran data dilakukan dengan uji Kolmogorov-Smirnov. Berdasarkan hasil analisis terlihat nilai Sig. dari semua kelompok data yang diperoleh dengan $t>0,05$ maka sebaran data berdistribusi normal. Uji homogenitas varians dilakukan dengan menggunakan uji Levene's Test for Equality of Variances. Untuk data hasil belajar XI AP 1 diperoleh signifikansi 0,275, begitu juga dengan XI AP 2 diperoleh signifikansi 0,485 yang keduanya melebihi 0,05. Dengan demikian data penelitian tersebut homogen. Uji multikolinieritas dilakukan dengan uji nilai VIF diketahui bahwa tidak terdapat nilai VIF (Variance Inflution Factor) masingmasing variabel bebas yang lebih dari 10. Hal ini menunjukkan model regresi bebas terbebas dari multikolinearitas dapat disimpulkan bahwa antara variabel bebas yaitu model pembelajaran inkuiri dan kemampuan berfikir kritis dengan variabel terikat yakni hasil belajar kimia tidak saling mempengaruhi.

Uji autokorelasi menggunakan Durbin-Watson test diperoleh nilai DW sebesar 1.923. Berdasarkan nilai Durbin Watson diperoleh, $1,65<1,92<2,35$, maka model regresi terbebas dari masalah autokorelasi. uji heteroskedasitas memperlihatkan bahwa titik-titik menyebar di atas dan di bawah angka 0 pada sumbu Y dan tidak membentuk pola tertentu. Sehingga dapat diketahui bahwa dalam regresi tidak terdapat hiterokedastisitas. Artinya dalam fungsi regresi pada penelitian ini tidak muncul gangguan karena varian yang tidak sama. Nilai sig. dari variabel model pembelajaran inkuiri terhadap hasil belajar 0.000, kesimpulan sig. > 0,05, berarti terdapat pengaruh model pembelajaran inkuiri terhadap hasil belajar, 2) nilai 
sig. dari variabel kemampuan berpikir kritis terhadap hasil belajar adalah 0.000, kesimpulan sig. > 0,05, ini berarti terdapat pengaruh kemampuan berpikir kritis terhadap hasil belajar, 3) hasil output analisis regresi diperoleh $F_{\text {hitung }} 52.402$ dengan sig. 0,000, karena >0,05 maka terdapat pengaruh model pembelajaran inkuiri dan kemampuan berpikir kritis secara bersama-sama terhadap hasil belajar.

\section{KESIMPULAN DAN SARAN}

Berdasarkan pengujian hasil penelitian ini dapat disimpulkan adalah: (1) Ada pengaruh yang signifikan pembelajaran dengan model inkuiri terhadap hasil belajar siswa, (2) Ada pengaruh yang signifikan kemampuan berfikir kritis terhadap hasil belajar siswa, (3) Ada pengaruh yang signifikan model pembelajaran inkuiri dan kemampuan berfikir kritis secara bersama-sama terhadap hasil hasil belajar siswa.

Implikasi hasil penelitian yang telah dilakukan adalah berupa implikasi teoritik: (a) Pembelajaran kimia dengan menggunakan model pembelajaran inkuiri dapat meningkatkan hasil belajar siswa, (b) Korelasi yang berkesinambungan antara pendekatan, metode, faktor internal pada siswa dapat meningkatkan hasil belajar yang lebih baik dan optimal. Implikasi praktis yakni pemilihan pendekatan model juga harus dijadikan pertimbangan dalam menentukan hasil belajar yang sesuai.

Saran yang dapat dikemukakan terkait dengan hasil penelitian ini adalah model pembelajaran Inkuiri dan kemampuan berpikir kritis perlu dikenalkan, diterapkan dan dikembangkan lebih lanjut kepada para guru, kepala sekolah dan praktisi pendidikan lainnya sebagai sebagai salah satu alternatif model pembelajaran pada mata pelajaran Kimia.

\section{REFERENSI}

Anna Poedjiadi. 2007. Sains Teknologi Masyarakat. Bandung: PT Remaja Rosdakarya.

Daniel, Fasko Jr. 2001. Education and Creativity. Creativity Research Journal. Bowling Green State University. 
Rusmiyati, A., \& Yulianto, A. 2009. Peningkatan Kemampuan Berpikir Kritis dengan Menerapkan Model Problem Based Instruction. Jurnal Pendidikan Fisika Indonesia, 5:75-78

Sochibin, Dwijananti, \& Marwoto. 2012. Penerapan Model Pembelajaran Inkuiri Terpimpin untuk Peningkatan Pemahaman dan Keterampilan Berpikir Kritis SiswaSD. Jurnal Pendidikan Fisika Indonesia. Semarang: Universitas Negeri Semarang, (5) 96-101.

Sugiyono. 2011. Metode Penelitian Pendidikan Pendekatan Kuantitatif, Kualitatif, $R \& D$. Bandung: Alfabeta CV.

Suharsimi Arikunto. 2002. Prosedur Penelitian. Jakarta: Rineka Cipta.

Sunardi. 2008. Kimia Bilingual SMA XI. Bandung: Yrama Widya.

Unggul Sudarmo. 2008. Kimia SMA. Jakarta: Erlangga.

Weiner, John M. 2011. Is There a Difference Between Critical Thinking and Information Literacy? A Systematic Review 2000-2009. Journal of Information Literacy. 